\title{
Competencias ciudadanas y autoridad en El Carmen del Darién: un estudio de caso en una institución escolar ${ }^{1}$
}

\section{Citizenship competences and Authority in El Carmen del Darien: case study in an education institutions}

\author{
Alejandro de Jesús Mesa-Arango* \\ (iD) : https://orcid.org/0000-0001-5637-2645 \\ Nilton Paz-Palacio** \\ (iD) : https://orcid.org/0000-0002-1625-1846 \\ María Rocelia Giraldo-Gil ${ }^{* * *}$
}

(iD) : https://orcid.org/0000-0002-8017-4443

Tipo de Artículo: Informes de Investigación y ensayos inéditos

Doi de artículo: 10.17533/udea.unipluri.19.1.03

Cómo citar este artículo:

Mesa-Arango, A., Paz-Palacio, N. y Giraldo-Gil, M.R. (2019). Competencias ciudadanas y autoridad en El Carmen del Darién: un estudio de caso en una institución escolar. Uni-pluriversidad, 19(1), 33-55 doi: 10.17533/udea.unipluri.19.1.03

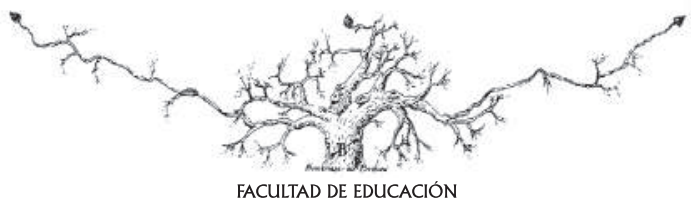

Recibido: 2018-11-20 • Aprobado: 2019-07-13

* Profesor titular de la Universidad de Antioquia. Facultad de Educación. Medellín - Colombia.

** Profesor de la Institución Educativa Agrícola La Unión del Bajirá. Profesor adscrito a la Secretaría de Educación del municipio de Riosucio - Departamento del Chocó

*** Profesora del colegio Mutatá. Profesora adscrita a la Secretaría de Educación del Municipio de Mutatá, en la región de Urabá, departamento de Antioquia. 
El infortunio de la región es su río Atrato y las privilegiadas condiciones territoriales de la culata del Darién y el Golfo en el contexto mundial. Paradójico: su ventura es su propia desdicha. (Osorio, 2006)

\title{
Resumen
}

Mediante un estudio de caso se indagó por el lugar de la autoridad en la formación ciudadana de un grupo de estudiantes del municipio de El Carmen del Darién, en el Departamento del Chocó. Esta se encuentra asociada, por un lado, a las formalidades del Gobierno Escolar en el marco de las competencias ciudadanas dentro de la institución educativa y, por el otro, fuera de ella, a la violencia ejercida por grupos armados al margen de la ley que se disputan el control del territorio desde hace varios años, dando lugar a la violencia como expresión de la autoridad.

Palabras clave: Carmen del Darién, competencias ciudadanas, autoridad, violencia.

\begin{abstract}
Through a case study, this research looked into the place of authority in citizenship education to a group of students from El Carmen del Darién, a municipality of Chocó Department. Place of authority is associated on the one hand, with formalities of the School Government in the framework from citizenship skills within the educational institution, and on the other, outside the institution, with the violence exercised by unlawful armed groups which are fighting for control of the territory for several years, leading to the violence as an expression of authority.
\end{abstract}

Keywords: Carmen del Darién, Citizenship Competences, Authority, Violence. 


\section{El Carmen del Darién}

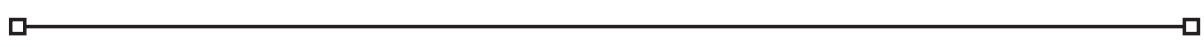

En esta investigación se indagó por el lugar de la autoridad en la formación ciudadana de un grupo de estudiantes del municipio de El Carmen del Darién. Esta se encuentra asociada, por un lado, con las formalidades del Gobierno Escolar en el marco de las competencias ciudadanas dentro de la institución educativa y, por el otro, por fuera de ella, a la violencia ejercida por grupos armados al margen de la ley.

"Carmen" es el nombre de una virgen, de la que han derivado múltiples tradiciones religiosas en las cuencas de los ríos Atrato y Baudó, en la costa pacífica colombiana y en algunos otros lugares del interior del país ${ }^{1}$; y "Darién" es el otro nombre que recibía el Atrato luego de su "descubrimiento" en 1511, por Vasco Núñez de Balboa.

Curbaradó es la cabecera del municipio de El Carmen del Darién, cuya marginalidad a nivel nacional no sólo es geográfica, social y económica sino también histórica. En la Internet se le asocia a una experiencia que representó la esperanza de alcanzar la paz en la Región, pero terminó en una gran frustración tras la violencia que se desató por parte de grupos armados en dos territorios que habían sido declarados "Comunidades de paz": Curbaradó y Jiguamiandó².

La fertilidad de sus tierras motivó a algunos empresarios apoyados por grupos paramilitares a implementar cultivos extensi- vos de palma de aceite. Muchos campesinos fueron obligados a vender a bajo precio su tierra, so pena de que "o vendía el propietario o vendía la viuda", como sentenciaban los "compradores". Otros debieron marcharse por amenazas contra su vida.

Con una población aproximada de 8.800 habitantes $^{3}$ y una superficie de $3.700 \mathrm{kms}^{2}$, el municipio limita al Occidente y al Norte con el municipio de Riosucio, del cual formó parte hasta el año 2000; al Oriente con los municipios de Mutatá y Dabeiba, localizados en el departamento de Antioquia; al sur con el municipio de Murindó, también en Antioquia y con Bojayá, en el departamento del Chocó; y al Suroccidente con el municipio de Bahía Solano en el departamento del Chocó.

Por su intrincada geografía, su espesa selva y la multiplicidad de ríos, caños y quebradas, así como por el acceso relativamente fácil a los recursos naturales y las vías fluviales para la extracción, el territorio que hoy ocupa el municipio fue propicio para la piratería y el contrabando por parte de personas llegadas de Europa; y del mismo modo, hoy en día, se presta para el tráfico de drogas y como corredor estratégico de grupos armados ilegales.

Entre finales de la década del setenta y principios de la del ochenta, la presencia del Estado se concretaba con algunas institucio- 
nes. El control territorial lo ejercía la Policía Nacional en la población de Curbaradó, una situación que se mantuvo hasta 1985 cuando, tras el primer ataque de las autodenominadas Fuerzas Revolucionarias de Colombia FARC, fueron retirados los efectivos de la Policía.

Desde principios de la década del ochenta hasta 1996, la guerrilla de las FARC y el autodenominado Ejército de Liberación Nacional (ELN) y los paramilitares, controlaban diversas zonas de la casi totalidad del territorio de Riosucio y el que hoy ocupa El Carmen del Darién. Ante la usencia del Estado estos grupos, además del control territorial, ejercían funciones de policía y administraban justicia.

En 1997, las fuerzas militares desplegaron una operación militar llamada "Génesis", con el objetivo de atacar a un reducto de las FARC en el municipio de Riosucio, en el Departamento del Chocó. Este hecho causó uno de los mayores desplazamientos de que se tenga noticia en Colombia. Cuatro mil personas debieron abandonar sus tierras que luego fueron utilizadas por ganaderos y grandes empresarios para el cultivo extensivo de palma.

Tres años más tarde, cuando el dominio era ejercido por paramilitares, fue creado El Carmen del Darién que comparte con los demás municipios del departamento del Chocó una economía basada en la extracción y, en menor escala, actividades de pesca artesanal y ganadería en el marco de un alto índice de necesidades básicas insatisfechas.

Sin que existiera equilibrio frente a la deforestación, se han reforestado alrededor de 1000 hectáreas de árboles maderables en territorios colectivos de las comunidades negras, principalmente en la cuenca del Do- mingodó. Las especies explotadas son, entre otras, cativo, cedro, roble, guina, guayacán, abarco, aceite, ceiba, pino amarillo, peine mono, tachuelo, incive y jagua. (Plan de Desarrollo municipal 2012-2015)

Por otra parte, se cuenta con un Centro de Salud con ocho profesionales para atender a una población que no tiene recursos para buscar atención médica en otro lugar. A este déficit en la atención se suma el congelamiento de la planta de profesionales y el accionar de los grupos al margen de la ley, que impiden la prestación del servicio en zonas alejadas de la cabecera municipal.

Como producto de esta situación del sistema de salud, se han presentado casos como el que informó el portal de eltiempo.com el 25 de marzo de 2007, sobre doce niños que murieron por desnutrición en el municipio y de otros nueve que debieron ser trasladados a Quibdó por la misma "enfermedad". Este y otros males como las parasitosis intestinales, las infecciones y la malaria son indicadores de la pobreza y el abandono que caracterizan a las comunidades indígenas y negras del Pacífico.

A nivel educativo, existe una muy baja inversión en infraestructura educativa y en la planta docente, tanto en la cabecera como en sectores periféricos. En consecuencia, los niños deben desplazarse largos trechos para llegar a la escuela más cercana, que, invariablemente, está desvencijada. Según un informe de la institución educativa en que se realizó esta investigación, en 2017, buena parte de la población no había superado la educación básica primaria.

De los ocho corregimientos y 45 veredas que administrativamente conforman El Carmen del Darién, sólo tres corregimientos y la cabecera cuentan con energía eléctrica, 
servicio que se presta de manera irregular, debido a los constantes problemas en las líneas de trasmisión. Para las comunicaciones, lo que más se utiliza es la telefonía celular que no está al alcance de la mayoría de la población. No hay agua potable, alcantarillado ni servicio de gas natural.

El empleo formal sólo se da mediante la contratación como empleado público en el municipio, que cuenta con 150 puestos de trabajo, distribuidos en administración municipal, educación, juzgado, registraduría, personería, centro de salud y una oficina para el desarrollo del departamento llamada CODECHOCÓ. Esto significa que sólo una mínima parte de la población tiene acceso a la seguridad social, sin que se garantice la estabilidad laboral ya que suelen darse cambios de empleados luego de las elecciones locales.

De la población restante que tiene capacidad laboral, unos se dedican a actividades como trabajo en fincas plataneras o ganaderas y otros a conseguir el sustento diario en la pesca y como jornaleros en la explotación forestal. Aunque se le reconoció a la población afro sus derechos ancestrales sobre la tenencia de la tierra y su uso para actividades agrícolas de pan coger, esto no ha sido posible por el accionar de grupos al margen de la ley y, en los últimos dos años, por la persecución y asesinato de líderes comunitarios.

Las formas de organización de los habitantes son insuficientes, debido a la inexistencia de espacios de participación, la cual se ha debilitado aún más a causa de la poca credibilidad frente a los procesos democráticos y políticos, sobre todo locales y regionales.

La población más joven se ve afectada por el aumento del embarazo precoz, las en- fermedades de transmisión sexual, el consumo de sustancias psicoactivas, los homicidios, la agresión sexual y la violencia intrafamiliar. Esta situación se ve agravada por la baja cobertura en la seguridad social y por la falta de conocimiento de la población sobre los mecanismos de defensa y promoción de sus derechos y de participación en la toma de decisiones que los afectan directamente. (Plan de desarrollo municipal 2012-2015).

Como se mencionó, los servicios de salud son bastante precarios y, por lo tanto, buena parte de la población recurre a prácticas de medicina tradicional para tratar algunas enfermedades a base de plantas; en ocasiones, estos tratamientos se apoyan también con algunas oraciones llamadas "divinas", a las que se acude para curar enfermedades como las parasitosis, el "bazo inflamado", las torceduras o las descomposturas y para detener una hemorragia.

Como en muchas otras poblaciones del país, la cultura puede constituir un bálsamo para el miedo. En El Carmen del Darién ésta tiene su expresión en las prácticas y creencias en salud, la alimentación y los estilos de vida y, como es de esperarse, en la religión, en la que ocupa un lugar destacado la celebración de las fiestas patronales.

Dentro de las creencias y costumbres de la región se resaltan los siguientes:

La Madre de Agua: es un espíritu representado en diferentes formas destacándose, entre ellas, la de las hojas de yarumo, al que se acude para "resolver" alguna contienda o para vengarse de un enemigo.

Sobre las hojas de yarumo se invoca a la Madre de Agua a fin de que persiga a los enemigos hasta el río y los ahogue. 
El Mohán: esta es una de las creencias más generalizadas en el territorio nacional. Dentro de las características comunes, sobre todo en el interior, se encuentran su gran fuerza, su vida solitaria en cuevas o dentro del monte y su maldad para hacer zozobrar embarcaciones o para robarse a las lavanderas más bellas.

En la versión de los pobladores de El Carmen del Darién, se trata de una persona con poderes, sabedora de "secretos".

Después de un tiempo de haber muerto, las personas con poderes se convierten en mohanes, muertos vivientes que salen en las noches a comer animales o incluso personas. A veces, puede reconocerse que alguien en vida era un mohán, cuando su cadáver aparece momificado, en cuyo caso debe realizarse un ritual a fin de que no siga causando daño a los habitantes.

El Gualí o Chigualo: es la ceremonia fúnebre.

Cuando es un niño el que muere, se ríe, se canta y se juega en su memoria, evocando el carácter alegre y espontáneo de los niños. Cuando es un adulto, en cambio, se reza nueve noches (la novena), se cantan "alabaos" o cantos fúnebres y, luego de las honras, que pueden darse a partir del segundo día de la novena, se hace una representación de la tumba, en el lugar de los rezos.

Durante la noche se reparte café, pan, cigarrillo y licor, y se juega dominó, cartas o bingo, ya que los allegados que acompañan a los dolientes generalmente tienden a pasar en vela en la casa en que se celebra la novena.

En un rincón del salón en que estuvo el féretro durante el velorio, rodeado por dos o tres costados con sábanas blancas a manera de cortinas y con velas encendidas, se continúan celebrando las novenas durante toda la noche.

En la última novena, a las cinco de la mañana, se levanta la tumba en medio de los alabaos y el llanto de los familiares y amigos.

La construcción de la casa: tal y como lo hacían los antepasados, que construían sus viviendas resguardadas de los animales salvajes y de cualquier otro peligro, los pobladores de El Carmen del Darién y de otras poblaciones aledañas, construyen sus casas en palafitos para protegerse de la creciente del río Atrato, cuyo nivel en época de invierno alcanza las calles e incluso el piso de las casas; una situación que puede durar desde varios días hasta varios meses. Para prevenirlo, los hombres recolectan materiales para agregar otro nivel a la casa con la ayuda de sus vecinos a fin de resguardar los enseres y poder dormir en las noches.

Las fiestas patronales: la Virgen del Carmen, la Niña María, San Francisco, la Virgen de las Mercedes y la Virgen de la Candelaria, son las fiestas que se celebran en el municipio. En ellas se congrega la mayor parte de la población, en medio de actividades deportivas, gastronómicas y culturales, animadas por los bailes folclóricos, dentro de los cuales está el tambeo, que es la expresión más representativa de la cultura de El Carmen del Darién.

El Tambeo: es una danza acompañada de canto y música. Para su ejecución se utiliza una tumbadora de 80 centímetros de largo cuyo sonido puede escucharse desde muy lejos. 
De origen africano, el tambeo llegó inicialmente a través de Vebaramá, de donde el señor Manuel José Blandón lo dio a conocer río abajo hasta llegar, en 1945, al Corregimiento de La Grande, cuando este pertenecía a Riosucio. Allí enseñó la danza y el canto que rápidamente fueron acogidos $\mathrm{y}$ son practicados hasta el día de hoy. Son ejecutados en las fiestas de la Virgen del Carmen.

El tambeo abre la fiesta, iniciando desde la víspera. Mientras suenan la tumbadora, la tambora, la requinta y los platillos, las mujeres se toman de las manos formando un círculo, al tiempo en que la cantaora entona versos de vivencias y anécdotas que suceden en las faenas del hogar, pero también en las de la pesca, en la siembra y la cosecha. Las mujeres hacen girar el círculo y van repitiendo lo que dice la cantaora. De pronto, un hombre irrumpe en la danza y rompe el círculo tomando como pareja a una de las bailadoras, con quien baila en ese lugar donde se rompió el círculo. Un segundo hombre, un tercero y otros más van también tomando pareja hasta que se forma todo el tambeo, en que hay ya varias parejas bailando, conforme se va reduciendo el círculo de mujeres al son de la música y los cantos.
Las costumbres alimentarias: están permeadas por los productos que tradicionalmente se cosechan como el plátano, el arroz, el maíz y la yuca y por la pesca artesanal, sobre todo de bocachico y de bagre.

Aunque se ha venido experimentando un proceso cultural en el que ha habido enriquecimiento con la inmigración de personas de diversas partes, también han aparecido problemas como el narcotráfico, la drogadicción, la delincuencia común, la prostitución y las enfermedades de transmisión sexual, entre otros.

La suma de los problemas y necesidades descritas, producto de la ausencia del Estado en El Carmen del Darién, ha ocasionado a su vez la re-emergencia de grupos paramilitares y la creación de organizaciones al margen de la ley integradas por "desmovilizados" de antiguos grupos que participaron en procesos de negociación, los cuales ejercen violencia para el control territorial en la cabecera y en las veredas en las que las instituciones educativas enseñan sobre competencias ciudadanas, con estrategias, contenidos y actividades que tienen poca relación con lo que se vive por fuera de ellas.

\section{COMPETENCIAS CIUDADANAS EN UN CONTEXTO EN CONFLICTO}

Al tiempo que aprenden sobre las competencias ciudadanas en las aulas de clase, los estudiantes de El Carmen del Darién deben desarrollar una competencia que permea toda la vida social, económica y política del municipio, la de saber sobrevivir en contexto.

Según Chaux (2004, p. 20) "las competencias ciudadanas son los conocimientos y habilidades que permiten que el ciudadano actúe de manera constructiva en la sociedad democrática". De acuerdo con el Ministerio de Educación Nacional (2006, p. 14), estas competencias están orientadas al logro de unos "estándares básicos" definidos como "criterios claros y públicos que permiten establecer cuáles son los niveles básicos de calidad de la educación a los que tienen derecho los niños y niñas de todas las regiones 
de nuestro país, en diferentes áreas del conocimiento...".

El tema de esta investigación fueron las Competencias Ciudadanas relacionadas con la dimensión de Convivencia y Paz, cuyo estándar general es que el estudiante participe en el desarrollo de propuestas a favor de la no-violencia en diferentes niveles. La pregunta que orientó la investigación fue la siguiente: ¿Cuál es el lugar de la autoridad en la formación ciudadana de un grupo de estudiantes del municipio de El Carmen del Darién?

En esta dimensión, en un municipio objeto de disputa territorial por parte del Estado y los grupos delincuenciales, resulta, cuando menos conflictiva, la pretensión de lograr el estándar de conocimientos que deben adquirir los estudiantes, expresados en primera persona en el texto correspondiente a los estándares básicos de competencias:

Comprendo que, para garantizar la convivencia, el Estado debe contar con el monopolio de la administración de justicia y del uso de la fuerza, y que la sociedad civil debe hacerle seguimiento crítico, para evitar abusos; Conozco las instancias y sé usar los mecanismos jurídicos ordinarios y alternativos para la resolución pacífica de conflictos: justicia ordinaria, jueces de paz, centros de conciliación, comisarías de familia; negociación, mediación, arbitramento; Conozco y respeto las normas de tránsito; Comprendo la importancia de la defensa del medio ambiente, tanto en el nivel local como global, y participo en iniciativas a su favor; Valoro positivamente las normas constitucionales que hacen posible la preservación de las diferencias culturales y políticas, y que regulan nuestra convivencia. (MEN, 2004 p. 24)
Un componente transversal de este estándar de conocimientos en la Competencia Ciudadana de convivencia y paz, correspondiente a los estudiantes participantes, es el de autoridad que, en el caso del municipio en general y de modo particular en la Institución, ha sido puesto en cuestión por los mismos estudiantes, en la medida en que toma diversos sentidos. En efecto, Rivera (2002), en un análisis que realiza sobre el concepto de autoridad en Hannah Arendt, advierte sobre el parentesco que se le da término autoridad con otros como poder, potencia, violencia, ley y legitimidad.

Siguiendo a Rivera (2002), tanto el concepto de autoridad como sus pretendidas equivalencias dan cuenta de mecanismos para alcanzar un fin que es el del mando de unos sobre otros. Sin embargo, es necesario comprender que en la autoridad como tal no se apela al poder, a la fuerza o a la violencia, sino que está cimentada en la legitimidad.

La autoridad no se define de forma expresa en las competencias, sino que se pluraliza para hacer referencia a las instancias jurídicas y legales a las que debe acudirse en caso de conflictos. Este aspecto sólo es posible cuando dichas autoridades administran justicia y mantienen el monopolio del uso de la fuerza, lo cual no sucede aún en varios lugares de Colombia, incluido El Carmen del Darién.

Por su parte, el poder reposa (o debería reposar) en una comunidad que es la que finalmente empodera a un grupo o incluso a un individuo que lo ha de representar ante diversas instancias del Estado. Empero esa relación, en los ejercicios de elección de los representantes de las comunidades, el poder puede llegar a instrumentalizarse a niveles 
insospechados, como ha pasado en Colombia. En lugar de la influencia, a través de las propuestas para la solución de problemas que podrían esperarse de los líderes políticos, se contemplan una serie de promesas que constituyen de suyo el juego interminable de prometer y no cumplir (asunto no solo conocido por los candidatos sino también por los electores), pero también de "persuadir" mediante la coacción armada en localidades como El Carmen del Darién y también con la compra de votos. Esta es una dinámica en la cual se ha llegado incluso a calcular cuánto podría costar la elección de un alcalde o de un gobernador.

De este modo, el arte de gobernar y de servir al pueblo, deviene en una lucha por el poder que, en el caso de Colombia, se ha ido centrando, cada vez más, en lo económico, aspecto que subyace a dos fenómenos comunes que han acompañado toda la historia de nuestro país: la corrupción y la violencia. Es válido afirmar que estos dos fenómenos, orientados desde niveles externos a las autoridades municipales, han hecho que, en municipios como El Carmen del Darién, la tenencia de la tierra, se pretenda trasladar a empresas nacionales y multinacionales y que aspectos como la libertad y la justicia sean "administrados" por agentes al margen del Estado y por lo tanto de la Ley.

Esa discusión entre lo contemplado en las competencias sobre la autoridad y la experiencia para los participantes en el municipio de El Carmen del Darién es el lugar en que se ubica esta investigación

\section{Metodología}

De acuerdo con las características de la investigación, se utilizó un enfoque cualitativo y el estudio de caso como método, con actividades de campo materializadas en tres técnicas: microrrelatos, entrevistas semiestructuradas y grupo focal. Se indagó por el lugar de la autoridad en la formación ciudadana de un grupo de estudiantes del municipio de El Carmen del Darién, asociado, por un lado, con las formalidades del Gobierno Escolar en el marco de las Competencias Ciudadanas dentro de la institución educativa y, por otro el otro, a la violencia por fuera de ella, ejercida por grupos armados al margen de la ley, con quienes el Estado ha venido disputando el control del territorio desde hace varios años.

\section{Participantes}

La población objeto de la investigación estuvo conformada por 19 estudiantes: siete hombres y doce mujeres (cinco de ellas con hijos). Trece viven en la cabecera municipal, cuatro en corregimientos del municipio y dos provienen de otros municipios. En tres de las familias de las que proceden los es- tudiantes, uno de los padres tiene seguridad social por ser empleado del municipio.

Los 19 estudiantes comparten las siguientes características: son desplazados, han sido víctimas de la violencia, sus edades oscilan entre los 15 y los 20 años, son afro- 
descendientes y la economía familiar está basada en la pesca artesanal y la agricultura (predominando el cultivo de plátano).

Antes de iniciar el proceso, se solicitó consentimiento a los estudiantes para su par- ticipación y un consentimiento informado a los padres de los menores de edad para que lo firmaran; en él se explicó que toda la información suministrada sería empleada con fines investigativos. También se solicitó autorización a las directivas de la Institución.

\section{LOS MICRORRELATOS}

Según Mesa (2011), el microrrelato es una técnica que se utiliza para la enseñanza de la literatura. En él pueden identificarse, como en el caso de esta investigación, aspectos relacionados con una experiencia con la autoridad, la cual da lugar a una entrevista posterior.

Aunque es breve, en el microrrelato se puede identificar el tiempo, el contexto, el hecho y los actores.

A los estudiantes se les pidió que relataran de forma voluntaria una experiencia con la autoridad que hubieran vivido o que conocieran por relato de otra persona en la comunidad o fuera de ella, en espacios como la familia, el barrio, la institución educativa, el municipio o en otro lugar cualquiera, fuera de éste.

Luego se recogieron los microrrelatos de once estudiantes. A manera de ilustración, se presenta uno de ellos:

"En el año 1997, mis abuelos vivían en el campo sembrando plátano, obtenían buenas cosechas de sus cultivos, pero tuvieron que salirse del campo porque llegaron unas gentes armadas, ocasionando disturbios y se vinieron para el pueblo. Ese fue su primer desplazamiento.

En el año 1998, tuvieron que salir las gentes corriendo de Curbaradó hacia Riosucio porque también se to- maron el pueblo. La gente agarró lo que podía llevarse y algunos se fueron con lo que tenían puesto.

Después regresaron en diciembre en el mismo año, pero las cosas ya no eran como antes. La gente tenía que vivir en medio de la violencia, (difícil) para los campesinos entrar a sus campos. Uno tenía que vivir con sus puertas cerradas porque cuando les daba la gana hacían sus disparos.

Cuando mis abuelos regresaron al campo encontraron los cultivos secos, desbaratados y tuvieron que iniciar desde cero, ese fue su segundo desplazamiento". (Microrrrelato de una estudiante, 14 de abril de 2017)

Una característica común de los microrrelatos de los participantes es que se refirieron principalmente a la violencia, tal y como lo deja ver el cuadro en que aparecen los hechos narrados que sucedieron en distintos lugares de la Región de Urabá.

Además de narrar un hecho violento, otra característica común en la mayoría de los relatos es que colocaron el año en que sucedieron los hechos, aunque algunos estudiantes eran aún muy niños y otros no habían nacido. En el siguiente cuadro se presenta una síntesis de los microrrelatos.

Fechas, lugares y hechos relacionados con la autoridad en los estudiantes participantes 


\begin{tabular}{|c|c|c|}
\hline Año & Lugar & Hecho narrado por los estudiantes \\
\hline 1980 & Curbaradó & $\begin{array}{l}\text { 1. El ejército robó las pertenencias de varias familias y las repartió } \\
\text { a otras }\end{array}$ \\
\hline 1996 & Pavarandó & $\begin{array}{l}\text { 2. Un enfrentamiento entre la guerrilla y grupos paramilitares } \\
\text { originó un desplazamiento masivo }\end{array}$ \\
\hline \multirow{3}{*}{1997} & \multirow{2}{*}{ Curbaradó } & $\begin{array}{l}\text { Un grupo armado irrumpió en una casa y obligó a la familia } \\
\text { abandonar el municipio }\end{array}$ \\
\hline & & Un grupo armado obligó a dos ancianos a abandonar el municipio \\
\hline & La Balsa & La guerrilla secuestró a un anciano \\
\hline 2000 & Belén de Bajira & $\begin{array}{l}\text { Un grupo armado asesinó a un hombre a sangre fría a la vista de los } \\
\text { pobladores }\end{array}$ \\
\hline 2008 & Curbaradó & $\begin{array}{l}\text { Un grupo de personas irrumpió en la Alcaldía y hurtó utensilios de } \\
\text { aseo que habían sido donados al municipio }\end{array}$ \\
\hline 2015 & Curbaradó & $\begin{array}{l}\text { Un grupo de personas denunció la manipulación de las elecciones } \\
\text { para alcalde en el municipio }\end{array}$ \\
\hline 2016 & Curbaradó & $\begin{array}{l}\text { Un joven fue agredido por la policía y encarcelado porque se negó } \\
\text { a identificarse en una requisa de la Policía. (Este relato fue narrado } \\
\text { por dos estudiantes) }\end{array}$ \\
\hline Sin dato & Curbaradó & $\begin{array}{l}\text { Los familiares de un joven que intentó entrar por la fuerza en una } \\
\text { oficina municipal atentaron contra quien lo había denunciado }\end{array}$ \\
\hline Sin dato & Curbaradó & $\begin{array}{l}\text { Algunos profesores del colegio no tienen autoridad y por lo tanto } \\
\text { los estudiantes "no les copian" }\end{array}$ \\
\hline
\end{tabular}

Fuente: creación propia

Para la entrevista semiestructurada que se realizó 15 días después de que los estudiantes presentaran microrrelatos, los estudiantes recordaban lo que habían narrado y fue notorio su deseo de ampliar lo que habían escrito y otros aspectos relacionados con el tema de la autoridad.

Luego se realizaron entrevistas no estructuradas a 11 estudiantes y un grupo focal con 12 estudiantes, en el que se profundizó sobre algunos de los subtemas que surgieron en la entrevista personal.

Los audios de las entrevistas y del grupo focal fueron transcritos y codificados. Los textos de las entrevistas aparecen precedidos de la letra "E" (Estudiante), seguida de otra letra que indica el código del estudiante y de un número. Por ejemplo: "EA21" es el texto 21 de la entrevista al estudiante A. Los textos del grupo focal aparecen codificados con las letras "GF" (Grupo focal), seguido de un número. Por ejemplo, "GF20” corresponde al texto 20 del grupo focal. Se realizaron varias lecturas de las transcripciones hasta lograr cierta familiaridad con las tendencias de las entrevistas y del grupo focal, con el de conformar un relato que diera cuenta del ejercicio de la autoridad en diversos contextos (dentro de la institución educativa y fuera de ella). De allí, emergieron las categorías de autoridad en la institución educativa y en el municipio. 


\section{Hallazgos}

\section{La autoridad en la Institución}

\section{Educativa}

En este apartado se describe el análisis de las respuestas de los estudiantes acerca de la autoridad en los microrrelatos, las entrevistas y el grupo focal, frente a pares representantes, que forman parte del Gobierno Escolar (Personero, Representante Estudiantil, Alcalde y Vicealcalde). En el análisis se presentan también aspectos de la autoridad de los miembros del Gobierno Escolar con respecto a la autoridad de los profesores.

Al preguntar si existe una autoridad reconocida entre los estudiantes, la primera figura que emerge es la del Personero Estudiantil, de quien se espera que esté atento a que sus compañeros "no se sobrepasen" y que, aun cuando sus profesores no hayan llegado, permanezcan en el aula. Es la "cabeza visible" para ellos porque fueron precisamente quienes lo eligieron, sentido en el cual su respuesta no puede ser otra que la de representarlos y cumplir con sus funciones, haciéndoles ver la conveniencia de atender a las normas para tener una buena convivencia.

No obstante, de acuerdo con las respuestas de los estudiantes, a muchos les cuesta trabajo "someterse" a la voz de otros estudiantes porque, a diferencia de los directivos y profesores, su autoridad está representada más por escucharlos cuando hay dificultades, por servirles de puente para evitar problemas que pueden terminar en una riña, $y$ por mediar entre ellos y los profesores o las directivas cuando hay alguna sanción que un estudiante no considera justa.
Algo similar pasa con el Representante Estudiantil que, aunque también es elegido por los compañeros de cada uno de los grados y que, como su nombre lo indica, debe representarlos ante cualquier instancia institucional, termina convirtiéndose en "una figura decorativa", pues en realidad tampoco ejerce autoridad alguna.

Cuando un profesor no se presenta a clase por alguna razón, se estipula que los estudiantes permanezcan en el salón y quien debe velar porque se cumpla esta norma es el Representante, sin embargo, ellos van saliendo sin prestarle ninguna atención, "como si él no existiera".

La autoridad tanto del Representante como del Personero están relacionadas con el hecho de que los estudiantes, sus pares, les "copien" o no, es decir que les presten o no atención y que pongan en práctica sus recomendaciones y sugerencias, pero también está relacionada con que acaten sus órdenes en el salón de clases, debido a que están facultados para ello en ausencia del profesor, o cuando los estudiantes no cumplen con una norma general como la que tiene que ver con llevar el uniforme de forma adecuada, por ejemplo.

La autoridad de los profesores de la Institución y la de los estudiantes que forman parte del Gobierno Escolar es percibida de modo diferente por los participantes en esta investigación. En efecto, cuando los profesores ordenan algo, a los estudiantes no les queda más remedio que obedecer sin discutir, porque si no lo hacen "llevan las de perder". Con el Personero y el Representante no pasa lo mismo, porque sus órdenes pueden ser discutidas o desatendidas, sin que el asunto "pase a mayores". 
Cuando se trata de reconocer los derechos de los estudiantes no pasa lo mismo que con el cumplimiento de los deberes. En ese caso, se reconoce la autoridad del Representante y la del Personero, más aún, dicha autoridad ${ }^{4}$ es demandada por el o los estudiantes afectados, ya que el desencuentro con un profesor o un directivo puede desencadenar sanciones disciplinarias.

Más allá de los procesos de elección de los representantes y de los contenidos del Manual de Convivencia de la institución, la gran diferencia entre la autoridad de los profesores y los representantes es que los primeros tienen un instrumento de mayor poder que es "la libreta de calificaciones", mientras que los representantes tienen "la libretica de disciplina”, casi sin ningún poder.

El desconocimiento de la autoridad de los representantes estudiantiles no sólo se da por parte de los estudiantes representados, sino también por parte de algunos profesores de la institución para quienes estos cargos no son significativos y, en consecuencia, les prestan poca o ninguna atención a las solicitudes de explicación sobre la situación de un estudiante en particular.

Debido a esto y a que las anotaciones sobre comportamientos y reclamos de los estudiantes realizados en la libretica no tienen mayores consecuencias y que generan una ruptura de relaciones entre los representantes y los representados, para uno de los estudiantes participantes en el grupo focal se trata de "cargos obsoletos".

Para remediar la asimetría en torno a la autoridad en los temas de los representantes estudiantiles, un estudiante señaló que debería haber un cambio en el Proyecto Educativo Institucional, de manera que allí se consagre que los llamados de atención y las notas que los profesores y los estudiantes entregan a los profesores directores de grupo tengan el mismo valor. En este sentido es que puede hablarse de las formalidades del Gobierno Escolar que atiende principalmente a las directrices que se dan desde el Ministerio a través de las competencias ciudadanas, en su componente de participación.

Se resalta que los estudiantes no ponen en cuestión la autoridad del Representante y la del Personero cuando les informan lo que en la institución se conoce como "buenas noticias" que, en este caso, tienen que ver con la desescolarización, tras la declaratoria de día cívico o cultural o debido a que un grupo de profesores debe recibir una capacitación o asistir a una reunión.

Por otra parte, más allá de la autoridad que tienen los profesores, el director de grupo o el Coordinador y la que no tienen el Personero ni el Representante, algunos estudiantes resuelven sus propios problemas por medio de la violencia:

“...Cuando nos vamos a dirigir a una persona que ha cometido un error o nos ha agredido verbalmente, lo agredimos físicamente". (EA 21.5 de mayo de 2017)

Existen otras figuras a las que se atribuye algo más de autoridad, ya que tienen más cercanía con los directores de grupo. Se trata del Alcalde y del Vicealcalde, quienes son elegidos por votación por salón de clases o aún por cada curso.

La función de ambos, más que velar por la disciplina dentro de la institución, es la de mediar en un conflicto entre los estudiantes, entre estos y los profesores o entre los estudiantes y las directivas del plantel, puesto que la información con que cuentan procede de forma directa de la Rectoría y cuando tienen algo que informar lo hacen al Rector. 
Aunque este tipo de relación no les confiere ninguna potestad para sancionar a los estudiantes, el Alcalde y el Vicealcalde, quien reemplaza al primero en caso de ausencia, sí sienten que su voz es más tenida en cuenta. De hecho, tienen una relación más estrecha y mayor confianza con los directores de grupo que la que pueden tener los representantes.

La consigna de uno de los estudiantes participantes en esta investigación, quien ejerce como Vicealcalde, se distancia de la pretensión del Personero y del Representante estudiantiles y tiene el tono de campaña electoral o de rendición de cuentas: "Tanto los alcaldes como los vicealcaldes estamos para servir, no para mandar" (GF).

El Alcalde y el Vicealcalde son vistos como "los sapitos" 5 debido a la relación estrecha que tienen con el director de grupo, la confianza que éste les tiene para dejarlos a cargo de alguna actividad y que ambos, de modo general, se ponen más del lado de los directores que de los estudiantes cuando hay algún problema.

"Yo no me siento con la autoridad ante nadie porque así como soy el Vicealcalde, también soy un estudiante. Todos somos iguales sólo que tengo un cargo que me acredita para llevar las inquietudes de los estudiantes al Consejo Directivo". (EA 37, 5 de mayo de 2017)

Si bien hay estudiantes que no tienen una buena imagen del Alcalde y el Vicealcalde, hay otros que los reconocen y los respetan, sobre todo cuando han visto en ellos a alguien imparcial que busca la armonía en el aula.

Además de la autoridad ejercida de manera formal dentro de la institución, un estudiante destaca que hay un escenario en que los estudiantes cumplen las normas sin el mayor reparo. Se trata de lo que sucede en la cancha de fútbol durante un entrenamiento de los estudiantes. Reciben las orientaciones del técnico y desarrollan la actividad ciñéndose de forma estricta a lo que él les indica, sin que estén los representantes, los profesores, las directivas ni el alcalde o el vicealcalde de la institución. "Hay un completo orden", dice un Representante Estudiantil participante en la investigación. La situación cambia cuando no aparece el técnico, puede tornarse caótica y en ocasiones terminar en una riña.

En los entrenamientos, tanto el técnico como los estudiantes tienen una meta impuesta por ellos mismos: sueñan con formar parte de una liga municipal o departamental en el mediano plazo; y a largo plazo, con formar parte de algún equipo reconocido. Son sueños compartidos por miles de jóvenes y niños de las escuelas de fútbol que hay en todo el país, los cuales sólo pueden alcanzarse con una disciplina que involucra, según el estudiante: el cumplimiento de horarios, dejar de asistir a eventos, de trasnochar y de beber licor, entre otros aspectos.

Cuando no está el técnico, el logro que se pretende es a corto plazo. El entrenamiento deviene en un partido en el que los participantes y los equipos que se conforman de forma espontánea utilizan las normas del juego al antojo de cada uno porque lo que se pretende, a toda costa, es ganar.

Por otro lado, de acuerdo con los participantes, hay una pirámide en la autoridad de la institución. En la parte superior está el Rector, de quien dependen los coordinadores, y de estos los profesores. En la base se encuentran los estudiantes, sin que haya un lugar determinado para los representantes, el personero y los alcaldes. 
En cuanto a la autoridad de los profesores, aunque se establece en torno a lo académico y lo administrativo para el funcionamiento de la institución, los estudiantes realizan una clasificación que depende de su flexibilidad o su inflexibilidad.

El "copiarle" o "no copiarle" a un profesor, es decir, prestarle o no atención a sus orientaciones son expresiones compartidas en el lenguaje de la institución entre los profesores y los estudiantes. "Copiarle" a un profesor es una expresión de halago a un profesor que tiene "dominio de grupo", mientras que el "no copiarle" es una expresión que significa falta de consideración y de respeto hacia un profesor, sobre todo cuando muestra mucha flexibilidad.

La autoridad de los profesores es legitimada en la medida en que existe una tradición al respecto en la institución, la cual es reforzada en la casa y en otros escenarios. Sin embargo, esta autoridad es ejercida, de acuerdo con algunos estudiantes, de manera autoritaria rayando incluso en la violencia verbal, gritando y dando órdenes "como si estuviéramos en un batallón", tal y como lo dice una estudiante en el grupo focal.

Algunos estudiantes no están de acuerdo porque es mucho más conveniente escuchar orientaciones o sugerencias como "arréglate el cuello" o "hagan el favor de...", utilizando el lenguaje que tanto se promueve. Lo que se requiere es, guardadas las diferencias, que los profesores se dirijan a los estudiantes con respeto y consideración, tal y como lo hacen el Personero y el Representante quienes, a pesar de esto, no son escuchados por la diferencia que existe entre la "libreta de calificaciones" (oficial) de los profesores y la "libretica de apuntes" (no oficial) de los representantes.
Otra estudiante en el grupo focal explica que ha habido injusticias, como cuando se les pone una nota de uno a todo el grupo por aspectos que no tienen que ver con los contenidos de un curso o con alguna otra actividad académica. Un caso como este se presentó cuando una profesora, aprovechando que un profesor no había ido al colegio, quiso adelantar su clase pero no pudo ya que el grupo estaba incompleto. En consecuencia, le puso una nota de uno a todos y no valieron los argumentos de los representantes y menos los de los demás estudiantes.

La libreta de calificaciones de los profesores se utiliza en algunas ocasiones como medio de coacción, pero también para mostrar el carácter del profesor mediante su determinación de mantener una nota que puede ser injusta. Es el caso del profesor que "se para en la raya", "habla con rigor", de tal modo que a los estudiantes "les toca someterse".

Esa forma de proceder ha ido calando en la cultura de la Institución, porque de hecho algunos estudiantes manifiestan que no les copian a aquellos profesores que se muestran más "pasivos" y "suaves", comprensivos y tolerantes, caracterizados porque son los que más se tardan en poner una anotación en el libro de disciplina:

"Al profesor que te hable suavemente te lo pasas por encima, no le haces caso, pues es una persona decente, no va a tomar represalias". (Código GF 35, 5 de mayo de 2017)

Resulta cuando menos paradójico que en el ejercicio de la autoridad por parte de los profesores hacia algunos estudiantes, estos últimos presten mayor atención a quienes les han tratado injustamente que a quienes los han tratado de una manera más cercana y comprensiva. 
Un patrón que se repite en los aportes de los estudiantes acerca del ejercicio de la $a u$ toridad se relaciona con la violencia verbal. Uno de ellos lo ilustra narrando la situación del Señor Rector al dirigirse a una profesora coordinadora de grupo a quien gritó y trató de mala manera, debido a que los estudiantes de su grupo estaban haciendo desorden. Fue un caso que generó violencia verbal también por parte de los estudiantes:

"Nosotros tuvimos que decirle a Rector que viniera al grupo, que fuera hombre, que tuviera el valor de venir a decirnos a nosotros... que no le pusiera quejas de la coordinadora, que no la sacara del salón para llamarle la atención". (GF 58. 5 de mayo de 2017)

Sin embargo, otro estudiante argumenta que los gritos y las palabras fuertes a veces son necesarias puesto que, en ocasiones, no quieren escuchar o no comprenden lo que se les está diciendo si no es utilizando ese tipo de lenguaje. En este sentido se manifestó un Representante Estudiantil participante en esta investigación para señalar que aunque lo habían elegido por votación en el grupo, no le prestaban atención debido a que él hablaba suave.

Otro estudiante señala que los gritos son necesarios en ocasiones también porque es de la única manera que algunos comprenden. Sólo a gritos llegan a entender aquellas cosas que son necesarias para su formación, para la vida, todo lo cual, en el caso de El Carmen del Darién, va más allá de la vida escolar, porque es claro, agrega el estudiante, que "el vigilante, esa libreta donde nos hacen las anotaciones", puede llegar a conocimiento de otras personas en el pueblo, lo cual generaría un rechazo "cuando salgamos a la vida pública" (GF 69. 5 de mayo de 2017).
Cuando se lee que la intención de los profesores es buena, otro participante anota que no puede calificárseles de buenos o de malos, porque si sus intenciones son buenas, entonces el profesor es bueno, así utilice los gritos o las sanciones.

Es importante tener en cuenta todas las descripciones anteriores. En algunos los estudiantes se han ido generando dos modelos de ejercicio de la autoridad, el de usar la violencia verbal y "pararse en la raya" utilizando como herramientas el libro de anotaciones y la libreta de calificaciones; y el otro, el del trato suave, al que una estudiante hace referencia, argumentando que ella "le copiaría más" y le tendría mayor respeto a un profesor que le hablara de manera más suave, a uno que le tuviera confianza para poder pedirle consejos sobre situaciones aún por fuera de la institución, en situaciones personales, como sucede en la actualidad con una profesora:

"A mí me gusta la directora que ahora tengo porque me da confianza, me da consejos que me instruyen. Ella quiere que yo sea una persona de bien" (Código GF 64, 5 de mayo de 2017)

Otra estudiante agrega que si los profesores dijeran las cosas de buena manera, los estudiantes les copiarían, les prestarían atención, porque el tono permite ver las intenciones, como la de orientarlos hacia el bien o simplemente la de regañarlos.

Sobre la autoridad en la institución se puede concluir que se manifiesta en diversas relaciones. En efecto, existe una relación entre estudiantes, en tanto pares, mediatizada por representantes estudiantiles como el Personero, para quien resulta contradictorio que no pueda ejercer su autoridad frente a quienes lo han elegido; al igual que al Represen- 
tante, piensa que la única autoridad a la que atienden los estudiantes es a la de los profesores, debido a la libreta de calificaciones que utilizan para el control y la autoridad sobre los estudiantes, aún en escenarios distintos al aula. Por fuera de la institución manifiestan que "le copian" a aquellos profesores que tienen, como sus padres o abuelos, una "autoridad buena", en el sentido que aquello sobre lo que los orientan no tiene que ver con aspectos escolares sino con aspectos personales.

Mientras que en la institución no haya conocimiento de un conflicto personal entre los estudiantes, estos no lo dan a conocer ni esperan una solución de parte de los profesores o los directivos; la "solución" se da entre ellos mismos, mediante las peleas por fuera de la institución, como se señaló antes.

A la libreta de calificaciones se suma la autoridad otorgada a los profesores, ya tradicional en el municipio, y los matices de autoritarismo de algunos que se expresa en el tono de la voz y en la inflexibilidad frente al incumplimiento de los compromisos o tareas de los estudiantes.

\section{Autoridades y "autoridades" en el municipio ${ }^{6}$}

De acuerdo con los estudiantes participantes, la autoridad legal que se ejerce en el municipio está representada en la Policía, el Consejo Comunitario y la Alcaldía, a la que se suma el Ejército y el Juzgado, mencionadas en algunos de los microrrelatos. Sin embargo, la presencia de la Policía es la que más representa la autoridad para ellos, debido a la urgencia para controlar la violencia que ejercen los grupos irregulares y por ende, para proteger la integridad y la vida de las personas.
Uno de los jóvenes señala que "sería fatal" que en el pueblo no hubiera presencia de efectivos de la Policía Nacional, ya que son los que representan a la autoridad legítima ${ }^{7}$, evitando que los grupos ilegales se tomen otra vez el municipio y ejerzan el control por medio de la intimidación y la violencia. De hecho, las autoridades legales no pueden extralimitarse en sus funciones y deben acatar las normas sobre el respeto a los derechos humanos, so pena de ser juzgados y condenados cuando se les demuestra que cometieron arbitrariedades.

"Es muy sencillo, si un policía mata a alguien en el municipio, el Gobierno lo tiene que pagar, pero si es la guerrilla o los paramilitares, las cosas se quedan así" (Código EI 29, mayo 6 de 2017)

Centrar la atención en la Policía casi como único representante de la autoridad legal tiene mucho que ver con el problema expresado en esta investigación y se relaciona con el hecho de que el control en El Carmen del Darién lo han ejercido los grupos ilegales a través de la violencia.

En los microrrelatos, las entrevistas y el grupo focal, ese es un tema reiterado. Las "autoridades al margen de la ley" han dejado heridas que aún no cicatrizan en los habitantes del municipio, sobre las cuales es preciso hablar y mantener en la memoria a fin de que no se repitan.

Ahora mismo están los paracos, se toman la autoridad, les dan órdenes a los jóvenes les dicen cómo se deben motilar, los amonestan, a los que consumen drogas los matan... (GF 79, mayo 6 de 2017)

Los microrrelatos de los estudiantes cubren el período de 1995 a 2012. Entre los casos que narran, los cuales sirvieron para 
iniciar las entrevistas, se destacan el asesinato o la desaparición de personas cercanas (familiares o vecinos), el desplazamiento forzado, la amenaza a personas para que abandonaran el pueblo y los asesinatos selectivos.

Como resultado de una amenaza por parte de las FARC, entre 1998 y 2003, no se podía navegar por el río Curbaradó una de las vías más importantes para el municipio. De modo similar "ellos" ordenaban el toque de queda. No se podía estar en la calle después de las nueve de la noche porque, como decía un estudiante participante:

"Nadie, pero nadie, les incumple porque ellos sí atentan contra la vida" (Código EF 83, mayo 6 de 2017)

Ningún miembro de la comunidad podía interceder frente a los paramilitares porque esto podía costarle la vida, debido a que era interpretado como contradicción a una orden. De este modo, desapareció el espacio público en que interactuaban las personas por medio de sus opiniones, en el que compartían sobre los problemas de la comunidad e intercambiaban alimentos.

A la violencia directa de los grupos ilegales, representada en los secuestros, asesinados, desplazamientos, amenazas y torturas, se agrega la violencia que traen consigo otras acciones para ejercer el dominio, dentro de las cuales estaban el control a la movilidad y la "administración de justicia".

Cuando una persona cometía una falta o un delito la golpeaban, "la arrestaban" o la ponían a trabajar en el campo, rozando una hectárea. A veces, según uno de los participantes, se trataba de castigos que se acompañaban de trato cruel, como ocurrió cuando a un joven lo denunciaron por robar y el castigo que le impusieron fue el de rozar casi por todo el pueblo amarrado a una cadena.

Un participante indica que cuando había una riña entre jóvenes, los paramilitares intervenían a nombre de la comunidad y se llamaban a sí mismos "los comandantes del pueblo" y ejercían el control mediante amenazas y castigos.

La lucha por el control territorial, más allá de la violencia ejercida por los diferentes grupos, estuvo abonada por el abandono por parte de las fuerzas armadas que, cuando se presentaban en el municipio, también solían acusar a los pobladores de ser auxiliadores de tal o cual bando.

En El Carmen del Darién, los padres evitaron durante un tiempo contar a sus hijos las atrocidades cometidas por los grupos armados, pero esto fue insostenible porque se vivía en el campo una guerra por el control territorial entre guerrilleros y paramilitares y los que quedaban en medio de ellos eran los pobladores del municipio.

Desde 2017 ha habido una mayor presencia de la fuerza pública, pero los pobladores temen que, como ha sucedido antes, esta presencia no sea permanente y que los paramilitares "retomen" el poder, lo cual es de hecho esperado por algunos comerciantes, quienes reciben protección a cambio de una "colaboración económica voluntaria". Fue así como sucedió con unos delincuentes que hurtaron el licor de un "estanco".

El comerciante puso la queja a los paramilitares, detuvieron a los delincuentes y los iban a asesinar públicamente, de no ser por la intervención de los miembros de la comunidad que se opusieron vehementemente 
a la ejecución. La pena para los delincuentes fue cambiada. En lugar de asesinarlos, los pusieron a dar vueltas por la cabecera llevando un letrero colgado del cuello en el que se leía "Soy ladrón".
"Ahí me parece que ejercieron la autoridad porque los muchachos se fueron del pueblo por miedo a que les hicieran algo" (Código EG 22, 5 de mayo de 2017)

\section{DiscusióN}

口

Desde los inicios de la vida republicana, la educación para la ciudadanía en Colombia se ha centrado en la acción, en concordancia con un modelo de ciudadano acorde con las necesidades del Estado (Mesa, 2009; Mesa Arango et al. 2015); y la acción, por su parte, se ha visto reducida a ejercicios de participación que se han centrado en la posibilidad de elegir y ser elegido, tal y como se deja ver en el sistema educativo a través de la implementación del Gobierno Escolar, en el marco de las competencias ciudadanas. Como se ha reiterado, este aspecto contrasta con la realidad de los estudiantes.

En ese sentido, esta investigación muestra el contraste entre lo que se instituye y lo que se da en la realidad, de cara a los anhelos de paz del país en los que se conjuga la esperanza con el miedo a lo que pueda pasar con la desmovilización de los grupos armados, en los lugares en que han tenido el control. Este es el caso del municipio de El Carmen del Darién, un municipio en el que el saber hacer en contexto devino en el saber sobrevivir en contexto.

La diferencia entre lo que se enseña y lo que se aprende en la institución y en otros espacios del municipio da cuenta de la descontextualización de las competencias ciudadanas y, de forma particular, de la distinción necesaria que se ha venido haciendo en la
Línea de Didáctica de las Ciencias Sociales y Formación Ciudadana de la Maestría en Educación de la Universidad de Antioquia, entre la educación para la ciudadanía institucionalizada (epc) y la formación ciudadana (fc). La primera con énfasis en lo jurídico y la segunda con énfasis en lo político (Benjumea, Gutiérrez, Jaramillo y otros, 2011).

En esta investigación se pusieron en juego ambos énfasis al contrastar el Gobierno Escolar y la cotidianidad de los estudiantes de una institución educativa del municipio de El Carmen del Darién, teniendo como eje las competencias ciudadanas, concretamente, en relación con la autoridad.

En ese sentido, González y Santisteban (2016) señalan que el carácter instrumental de la educación en la actualidad ha hecho que, al descontextualizarse, la denominada formación ciudadana pierda su norte para ubicarse al lado de la necesidad de incluir algo parecido en los planes de estudio, de acuerdo con las directrices del Ministerio de Educación Nacional. Esta descontextualización de la educación para la ciudadanía no sólo tiene que ver con los aspectos mencionados en El Carmen del Darién, sino también con lo poco o nada que los profesores de la institución conocen a los sujetos en cuya formación participan. 


\section{Conclusiones}

El propósito de esta investigación, además de poner como objeto la propia práctica como maestros, fue el de aproximarnos a la intersección entre el modelo institucional de ciudadano y la realidad de los estudiantes de la institución. En este caso, se tuvo como tema el de la autoridad, precisamente porque en el modelo de ciudadano institucional se contemplan las competencias ciudadanas de democracia y paz en un municipio que ha vivido al margen del desarrollo territorial y nacional y en donde la supervivencia constituye una lucha diaria, no sólo por lo que significa la consecución del sustento sino también por la conservación de la vida misma, frente a la amenaza permanente de la ocupación del territorio por parte de grupos armados.

Más allá de la posibilidad de ser escuchados por sus compañeros, la autoridad de los representantes, personero, alcalde y vicealcalde estudiantiles no es comparable con la que tienen los profesores y las directivas. No existen directrices claras en el Manual de Convivencia que les permitan el ejercicio de dicha autoridad, razón por la cual, como sucede también en otras instituciones educativas, el Gobierno Escolar no constituye un ejercicio de participación como tal, sino la puesta en escena de un requerimiento del Ministerio de Educación Nacional.

Por otro lado, para los estudiantes, la autoridad de las instituciones del municipio está representada por los funcionarios de la Alcaldía, pero principalmente por la policía y el ejército, los cuales se disputan la "autoridad" y el control del territorio con grupos armados ilegales. De esta forma emerge el uso de la fuerza y la violencia como formas de autoridad tanto legales como "ilegales".
Lo que se conoce como "las autoridades" tiene dos connotaciones para los estudiantes. Una es la legal, conformada primordialmente por el Ejército y la Policía ${ }^{9}$ y otra la ilegal, representada por los grupos de guerrilla y los paramilitares. Ambos tipos de autoridad son caracterizados por la fuerza y por el potencial uso de la violencia, ejercida por grupos delincuenciales cuyos "procesos" terminan en la muerte, el desplazamiento, la amenaza o la desaparición e incluso en la humillación o el trabajo forzado en el campo, como sucede con los delincuentes comunes. Una diferencia es que los abusos de la "autoridad legal" pueden denunciarse, mientras que los de la "autoridad" ilegal no.

La vida y la integridad siempre son puestas en juego cuando hay un encuentro entre los agentes, legales o ilegales armados y la población. Todo esto tiene que ver, precisamente, con la falta de garantía de la protección de la vida y la integridad por parte del Estado, a través de los juzgados y sus debidos procesos, la Procuraduría, la Fiscalía, la Personería y oficinas como la de Bienestar Familiar o de protección a la población vulnerable. Contrario a esto, han sido las mismas personas de la Comunidad quienes han enfrentado los problemas exponiendo su vida e integridad y la de sus familias.

Frente a este panorama, un manual de convivencia en la institución es algo así como una puerta en medio del desierto, en la medida en que se trata de conciliar diferencias entre los estudiantes que resultan ínfimas si se tiene en cuenta la realidad del municipio y el control que han ejercido los grupos ilegales antes y después de su fundación. 
El modelo que emerge del Manual de Convivencia Institucional propone la formación de los educandos a la luz de valores para la sana convivencia, en el marco del respeto por las diferencias entre personas y grupos, promoviendo la autonomía y la libertad. Esto resulta cuando menos paradójico en la medida en que el colegio mismo ha sido escenario de reuniones de esos grupos al margen de la ley.

Otros de los elementos contenidos en el Manual tienen que ver con la promoción de la participación, la inclusión y la proyección en la comunidad, asuntos que en realidad no presentan mayor problema en la comunidad, debido a que ésta se reconoce como negra, indígena y campesina y ha compartido sus orígenes y su desarrollo desde hace más de un siglo a lo largo de la cuenca del Atrato.

Desde luego, en el Manual de Convivencia también se contempla la garantía de los derechos humanos de los cuales, como se ha mostrado a lo largo de este escrito, no tiene participación la Comunidad de El Carmen del Darién, a causa de la ausencia casi total del Estado.

En otro apartado del Manual se lee que en la institución se deben "Proporcionar momentos y espacios de interacción, para fortalecer la vivencia de la democracia y la construcción de una cultura de paz". La paz es tal vez la necesidad más apremiante no sólo de la institución sino del municipio, el departamento y la región y se expresa en lo que podría llamarse una resistencia a ser sometidos u obligados a participar en favor de los intereses de tal o cual grupo.

De hecho, algunos de los jóvenes participantes en esta investigación han expresado sus dudas con respecto al proceso de paz con las FARC, debido a que los desplazados por este grupo insurgente "tienen mucho miedo" de regresar a su tierra... "Temen por su vida y la de su familia".

Los estudiantes no creen en el Acuerdo para la Terminación Definitiva del Conflicto que se firmó entre el gobierno del presidente Juan Manuel Santos y las FARC en Bogotá el 24 de noviembre de 2016, tras largas conversaciones en Oslo y en la Habana. No creen en las intenciones de este grupo guerrillero debido a varias razones:

- No todos los frentes se van a desmovilizar

- El Gobierno no atendió a la votación en la que ganó el "no"

- En tiempo de elecciones, los guerrilleros que se quedan en el monte irán a las cabeceras a obligar a la gente a que vote por sus candidatos.

- La guerra que antes se daba en las márgenes de los pueblos, ahora va a llegar a las cabeceras y a las capitales

- Los paramilitares desmovilizados se enfrentarán con los guerrilleros desmovilizados

Tampoco comparten el hecho de que los ex guerrilleros estén recibiendo "beneficios", luego de todo el daño que han hecho no sólo en la región sino en el país entero. Sobre su participación en política, uno de los estudiantes indica:

"Si estos hombres hacían mal en el monte, como irá a ser allá en el Senado" (Código GF 99. Mayo 6 de 2017)

''El que es, no deja de ser". (Código GF 108. Mayo 6 de 2017)

Por último, el Manual de Convivencia contempla que la institución debe "ofrecer condiciones pedagógicas y ambientales para hacer posible una formación ajustada al mo- 
delo institucional y a las exigencias del ciudadano". Esto genera una pregunta con respecto a las competencias ciudadanas acerca de lo que los estudiantes como ciudadanos deben "saber hacer en contexto". La pregunta es ¿En cuál contexto?

\section{Notas}

1. Otros municipios del país relacionados con este nombre son: El Carmen de Viboral (Antioquia), El Carmen (Norte de Santander), El Carmen de Chucurí (Santander), El Carmen de Bolívar (Bolívar), El Carmen de Carupa (Cundinamarca), El Carmen de Apicalá (Tolima), El Carmen de Atrato (Chocó) y Pijiño del Carmen (Magdalena),

2. Jiguamiandó es un corregimiento que agrupa varios poblados en las márgenes del río de ese mismo nombre.

3. Fuente: http://www.municipios.com.co/choco/carmen-del-darien. Recuperado el 11 de septiembre de 2018. En Carmen del Darién es uno de los municipios que más desplazados recibe.

4. Al referirse a la autoridad del Personero y del Representante Estudiantil, algunos estudiantes hacen "comillas" con los dedos índice y medio de ambas manos.

5. "Sapos" en Colombia es una expresión que hace referencia a personas que espían para luego poner una queja ante una autoridad. Aquí se utiliza en diminutivo para referirse al papel que hacen Alcalde y el Vicealcalde en el colegio.

6. Algo que hacían algunos de los estudiantes en la entrevista y en el grupo focal, para referirse al control territorial por parte de los grupos ilegales, era alzar las manos a la altura de la cabeza y flexionar los dedos índice y medio de ambas en dos o tres ocasiones, lo cual representa el encerrar entre comillas aquello a lo que se van a referir, en este caso a la autoridad de los grupos ilegales.

7. El participante hace una distinción señalando a la Policía como la autoridad legítima, para diferenciarla del ejercicio de la autoridad "ilegítima" de los grupos al margen de la ley.

8. Licorería

9. Los alumnos consideran, además, como autoridades en el pueblo al alcalde y al consejo comunitario, a través de cuyas instancias pueden hacerse cumplir los derechos de la población. No obstante, no resaltan la autoridad en términos similares a como lo hacen con los grupos armados

\section{Bibliografía}

Alcaldía municipal de El Carmen del Darién. Plan de desarrollo 2012- 2015. Primero el Desarrollo.

Arendt, H. (2005). De la historia a la acción. Barcelona: Paidós.

Arendt, H. (2007). La condición humana. Buenos Aires: Paidós. 
Benjumea, M., Gutiérrez, A., Jaramillo, O., Mesa, A. y Pimienta, A. (2011). Formación ciudadana (FC) y Educación para la Ciudadanía (EpC). Aproximaciones conceptuales y mínimos compartidos. Revista Temas, (5), 211-224

Chaux (2004). Aproximación integral a la formación ciudadana. En: Chaux, E. Lleras, J. Velásquez, A. (Eds). Competencias ciudadanas: de los estándares al aula: una propuesta de integración a las áreas académicas (pp. 13-25). Bogotá: Ministerio de Educación Nacional y Universidad de los Andes. Ediciones Uniandes

González-Valencia, G. A. y Santisteban-Fernández, A. (2016). La formación ciudadana en la educación obligatoria en Colombia: entre la tradición y la transformación. Educ. Educ., 19(1), 89-102. DOI: 10.5294/edu.2016.19.1.5

Mesa, A. (2011). El juicio de los espectadores de Hannah Arendt. Entre la educación para la ciudadana y la formación ciudadana en la Universidad. Tesis doctoral. Doctorado en Educación. Universidad de Antioquia. Medellín

Mesa, A. (2009). La formación ciudadana en Colombia. Uni-pluriversidad, 8(3),1-9.

Mesa Arango, A., Romero Reyes, L., \& Vásquez Sánchez, F. (2015). Modelos ejemplares y formación ciudadana. El caso de los estudiantes de la institución Educativa Antonio Roldán Betancur del municipio de Necoclí, Antioquia. Uni-pluriversidad, 15(1), 65-75.

Ministerio de Educación Nacional (2004). Formar para la ciudadanía sí es posible. Bogotá: Ministerio de Educación Nacional.

Ministerio de Educación Nacional. (2006). Estándares básicos de competencias en lenguaje, matemáticas, ciencias y ciudadanas: guía sobre lo que los estudiantes deben saber y saber hacer con lo que aprenden. Bogotá: Magisterio

Municipio de El Carmen del Darién "Primero la Comunidad" (2012). Plan de desarrollo 2012-2015.

Osorio Gómez, J. (2006). Pueblos itinerantes de Urabá. La historia de las exclusiones. Retrato. Tesis de maestría en historia latinoamericana. Andalucía: Universidad Internacional de Andalucía

Rivera, A. (2002). Crisis de autoridad: el concepto de autoridad en Hannah Arendt. Daimon Revista Internacional de Filosofia, (26), 87- 106.

\section{Cibergrafía}

\section{口-}

https:/www.eltiempo.com/archivo/documento/CMS-3491860 Recuperado el 20 de agosto de 2017 